\title{
Photochemistry of Common Xanthene Fluorescent Dyes as Efficient Visible-light Activatable CO-Releasing Molecules
}

Marek Martínek, ${ }^{1}$ Lucie Ludvíková, ${ }^{1}$ Mária Šranková, ${ }^{2}$ Rafael Navrátill, ${ }^{3}$ Lucie Muchová, ${ }^{2}$ Jiří Huzlík, ${ }^{4}$ Libor Vítek, ${ }^{2,5}$ Petr Klán, ${ }^{1,6}$ Peter Šebej ${ }^{1, *}$

${ }^{1}$ RECETOX, Faculty of Science, Masaryk University, Kamenice 735/5, D29; 62500 BrnoBohunice, Czech Republic

${ }^{2}$ Institute of Medical Biochemistry and Laboratory Diagnostics, General University Hospital in Prague and $1^{\text {st }}$ Faculty of Medicine, Charles University, Kateřinská 32, 12108 Praha 2, Czech Republic

${ }^{3}$ Department of Organic Chemistry, Faculty of Science, Charles University, Hlavova 2030/8, 128 43, Prague, Czech Republic

${ }^{4}$ Transport Research Centre (CDV), Líšeňská 33a, 63600 Brno-Líšeň, Czech Republic

${ }^{5} 4^{\text {th }}$ Department of Internal Medicine, General University Hospital in Prague and $1^{\text {st }}$ Faculty of Medicine, Charles University, Kateřinská 32, 12108 Praha 2, Czech Republic

${ }^{6}$ Department of Chemistry, Faculty of Science, Masaryk University, Kamenice 735/5, A08; 62500 Brno-Bohunice, Czech Republic

\begin{abstract}
Xanthene derivatives are organic dyes, some of which are routinely used in different chemical and biological applications, including human medicine. In this work, we investigated the photochemistry of some of the most common ones, fluorescein, eosin Y, and rose bengal, and major products of their photodegradation using optical spectroscopy, NMR, chromatography and mass spectroscopy techniques. These substances, usually considered (photo)chemically stable, were found to liberate carbon monoxide (CO) in $40-80 \%$ chemical yields upon extensive irradiation with visible light in aqueous solutions during their multistep concomitant degradation processes. In addition, a number of low-mass secondary photoproducts, such as phthalic and formic acids, were identified in the irradiated mixtures. We demonstrate that these common fluorescent dyes can also be considered as visible-light activatable carbon monoxide (CO)-releasing molecules (photoCORMs) under specific conditions with potential biological implications.
\end{abstract}

\section{Introduction}

One of the main prerequisites for the chemical and biological applications of organic dyes, for example, as fluorescent tags, ${ }^{1,2}$ laser dyes, ${ }^{3}$ or $\mathrm{pH}$ indicators, ${ }^{4,5}$ is their thermal and photochemical stability. Fluorescein (1), eosin Y (2), and rose bengal (3, Figure 1) are such frequently used xanthene chromophore-based dyes that it is often not considered important in their applications that the substances could undergo chemical or photochemical degradation. 
<smiles>O=C([O-])c1ccccc1-c1c2ccc(=O)cc-2oc2cc([O-])ccc12</smiles>

1<smiles>O=C([O-])c1ccccc1-c1c2cc(Br)c(=O)c(Br)c-2oc2c(Br)c([O-])c(Br)cc12</smiles>

2<smiles>O=c1c(I)cc2c(-c3c([18O])c(Cl)c(Cl)c(Cl)c3Cl)c3cc(I)c(O)c(I)c3oc-2c1Cl</smiles>

3

Figure 1. Structures of a) fluorescein (1), b) eosin Y (2), and c) rose bengal (3) in an aqueous solution at $\mathrm{pH}=7.4$.

Early studies of the chemical behavior of excited xanthene derivatives were focused on the initial chemical steps. ${ }^{6}$ Time-resolved spectroscopic techniques allowed us to understand the photophysics of, for example, eosin ${ }^{7,8}$ and fluorescein, ${ }^{9}$ but to the best of our knowledge, stable products formed from 1-3 upon irradiation have never been identified or isolated. Lindquist detected several different early intermediates in his thorough study, ${ }^{9}$ and Imamura showed that the photodegradation of fluorescein is irreversible. ${ }^{10}$ Low-mass products are often released upon extensive photochemical degradation of organic molecules. Conventional analytical techniques easily overlook these, sometimes gaseous, molecules or fragments.

Photochemical production of carbon monoxide (CO) has been reported for many different compounds. ${ }^{11-13}$ It has already been demonstrated that the photochemistry of some xanthene derivatives can result in CO liberation. ${ }^{14,15}$

Carbon monoxide (CO) is an essential biogenic gasotransmitter ${ }^{16}$ that interacts with metalloproteins. ${ }^{17,18} \mathrm{CO}$ in mammalian organisms is avidly bound to hemoglobin $(\sim 80 \%),{ }^{19}$ whereas it has various regulatory and protective functions, such as protection during hypoxia, ${ }^{20}$ vasodilatation, ${ }^{21}$ bactericidal ${ }^{22}$ and anti-inflammatory effects, ${ }^{23-25}$ promotion of wound healing, ${ }^{26}$ reducing tumor growth, ${ }^{27-29}$ in the remaining part of plasma under physiological concentrations. $\mathrm{CO}$ has also emerged as a promising therapeutic agent for acute kidney injury, a previously unmet medical need. ${ }^{30}$ However, at higher blood concentrations, ${ }^{20}$ it is a deadly poisonous agent inhibiting the binding of oxygen to hemoglobin, thus causing hypoxia ${ }^{31,32}$ and dysregulation in redox pathways. ${ }^{33}$

Direct CO inhalation is the simplest delivery mode to mammalian organisms, ${ }^{34}$ followed by the instant formation of $\mathrm{COHb}$ in blood and slow non-enzymatic release, which does not allow precise control over its dosing and release kinetics. Current efforts to develop more stable and reliable CO-delivery methods, using small molecules that release $\mathrm{CO}$ upon activation (COreleasing molecules; CORMs), allow for a more precise temporal and spatial control over its release. ${ }^{11,35}$

Since then, numerous strategies for the controlled CO release have been developed. ${ }^{36,37}$ Light can trigger CO liberation from various molecules, such as carbonyl complexes ${ }^{38,39}$ or metalfree molecules. ${ }^{11,14}$ Rational design of such photoactivatable CORMs (photoCORMs), based on, for example, xanthene ${ }^{14}$ or BODIPY moieties, ${ }^{40}$ allowed for fine-tuning of their optical and chemical properties. The bathochromic shift of absorption spectra toward the visible and nearinfrared region (i.e., a phototherapeutic window), ${ }^{41-43}$ is especially important for bioapplications.

The potential therapeutic use of photoCORMs depends on the same legal and economic considerations as for other drugs. In general, the most economically demanding part of this process are the appropriate clinical trials as a requirement for approval of a substance for medical use. 
The standard clinical trials involve toxicity testing of potential drug candidates and their metabolites and impurities. The potential phototoxicity of chemicals used in human medicine is much less explored. ${ }^{44}$ Mechanisms of phototoxicity involve, for example, photosensitization $^{45}$ or degradation to a toxic product. ${ }^{46}$ Photochemically induced adverse effects of drugs are often unreported or misdiagnosed. ${ }^{47,48}$ Some compounds, such as diagnostic dyes, are used in conjunction with optical irradiation. For example, rose bengal (3) can be used in photodynamic antimicrobial therapy ${ }^{49}$ and photochemical tissue bonding. ${ }^{50,51}$

In this work, we decided to study photochemical properties of three common visible lightabsorbing xanthene dyes: fluorescein (1, the prototypical fluorophore) ${ }^{52} \operatorname{eosin} \mathrm{Y}(\mathbf{2}$, a widely used photocatalyst $)^{53,54}$ and rose bengal (3, a common triplet and singlet oxygen sensitizer $)^{55,56}$ (Figure 1). Fluorescein is approved by EMA, FDA, and other regulatory agencies for its use in human medicine, for example, for diagnostic purposes (in ophthalmology, ${ }^{57}$ urology $^{58}$ and neurosurgery). ${ }^{59}$ It is also featured on a WHO List of Essential Medicines as an ophthalmic diagnostic agent. ${ }^{60,61}$ Eosin $\mathrm{Y}$ is used for staining of histological fixatives, ${ }^{62}$ and rose bengal can be utilized in ophthalmology. ${ }^{63}$ We studied the photochemistry of these dyes with optical spectroscopy, NMR, chromatography and mass spectroscopy techniques. We show that the compounds are photolyzed to produce $\mathrm{CO}$ and other low-mass photoproducts upon extensive irradiation. Biological aspects of the $\mathrm{CO}$ photoproduction from fluorescein are discussed in a currently submitted article. ${ }^{64}$

\section{Results and Discussion}

Photophysical Properties. Absorption and emission spectra of fluorescein (1), eosin Y (2), and rose bengal (3) in an aqueous buffer (phosphate-buffered saline; $(1 \times) \mathrm{PBS}, \mathrm{pH}=7.4, I=$ $0.1 \mathrm{~mol} \mathrm{dm}^{-3}$ ) solution are shown in Figures 2 and S23-S25, and an overview of the basic spectroscopic data is given in Table 1 .

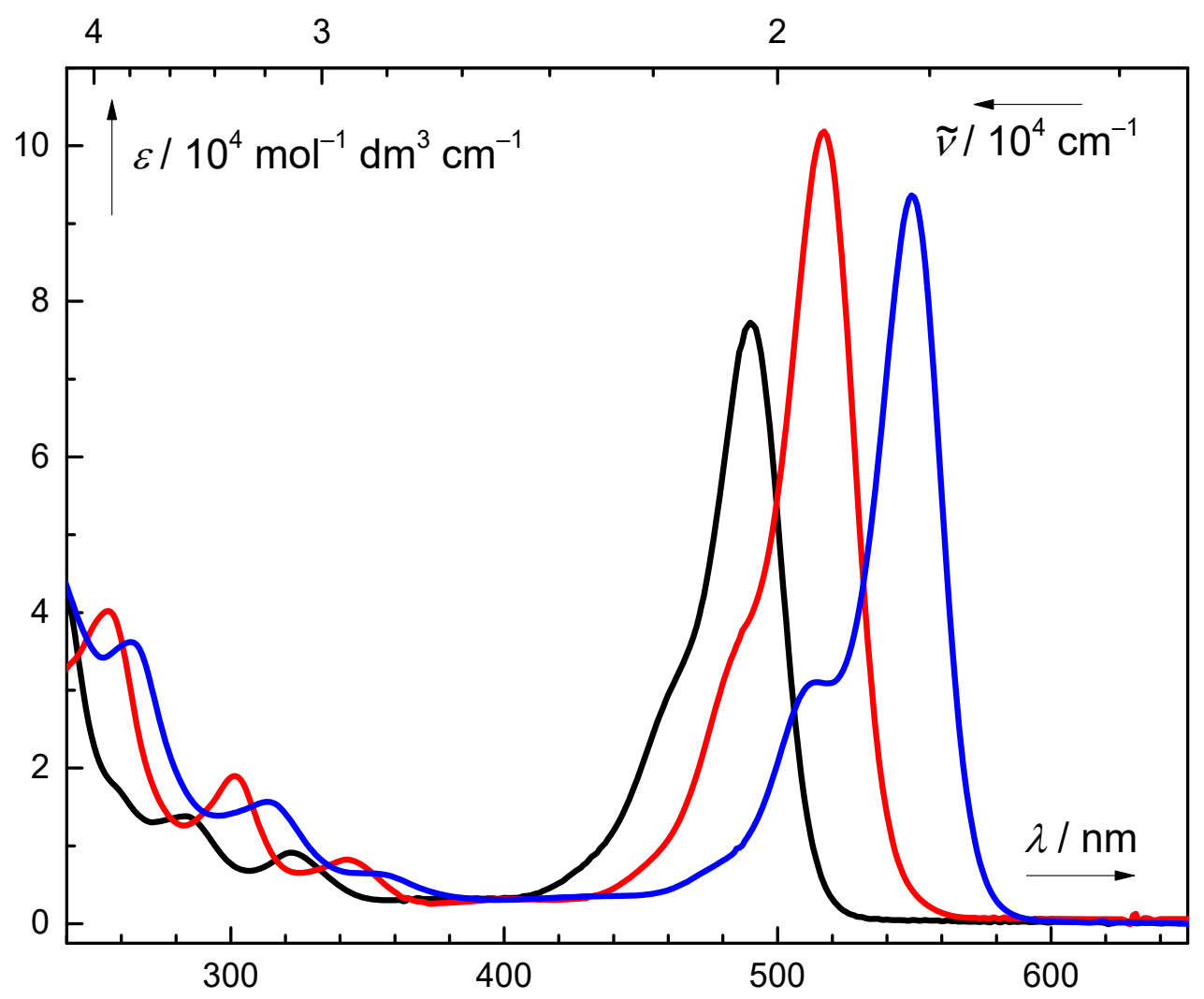


Figure 2. Absorption spectra of fluorescein (1; black), eosin Y (2; red) and rose bengal (3; blue) in PBS $(c$ dye $\left.) \sim 1 \times 10^{-5} \mathrm{~mol} \mathrm{dm}^{-3}\right)$.

Dyes 1-3 have their major absorption bands centered in the green region with $\lambda_{\max }(\mathrm{abs})$ in the range of 490-550 $\mathrm{nm}$ (Figure 2, Table 1). The shape of the bands and the positions of maxima exhibit only relatively small solvatochromic shifts. ${ }^{65-68}$ The compounds are fluorescent with fluorescence quantum yields $\left(\Phi_{\mathrm{f}}\right)$ spanning from 0.02 for $\mathbf{3}$ to 0.93 for $\mathbf{1}$ in an aqueous solution at $\mathrm{pH} \sim \geq 7.4$. Fluorescence represents the major deactivation for excited fluorescein. The compounds exhibit only small Stokes shifts $\left(15-25 \mathrm{~cm}^{-1}\right)$, which is a typical feature of xanthene dyes. ${ }^{5,69}$ The excitation spectra closely match the absorption spectra (Figures S23-S25).

Table 1. Photophysical Properties of 1-3 in Aqueous Solutions. ${ }^{a}$

\begin{tabular}{|l|l|l|l|l|}
\hline Compd & $\lambda_{\max }(\mathrm{abs}) / \mathrm{nm}$ & $\varepsilon / \mathrm{dm}^{3} \mathrm{~mol}^{-1} \mathrm{~cm}^{-1}$ & $\Phi_{\mathrm{f}}{ }^{b}$ & major deactivation pathways \\
\hline $\mathbf{1}$ & $490(490)^{70}$ & $\begin{array}{l}7.69 \times 10^{4}(0.1 \mathrm{~mol} \\
\left.\mathrm{dm}{ }^{-3} \mathrm{NaOH}\right)^{70}\end{array}$ & $0.93^{70}$ & fluorescence \\
\hline $\mathbf{2}$ & $517(517)^{71}$ & $9.9 \times 10^{472}$ & $\begin{array}{l}0.43^{73} \\
0.20^{67}\end{array}$ & $\begin{array}{l}\text { fluorescence, } \text { isc }^{c}\left(\Phi_{\text {isc }}(\mathrm{pH} 9)\right. \\
=0.7 \pm 0.1 i^{74} \Phi_{\text {isc }}\left(\mathrm{H}_{2} \mathrm{O}\right)=0.4 \\
\pm 0.03)^{75}\end{array}$ \\
\hline $\mathbf{3}$ & & & & $\operatorname{isc}^{c}\left(\Phi_{\text {isc }}=0.98\right)^{76}$ \\
\hline
\end{tabular}

${ }^{a}$ In aqueous solutions at $20{ }^{\circ} \mathrm{C}$ : PBS buffer (see Supporting Information), unless stated otherwise. The values from the literature are given in parentheses. ${ }^{b}$ Quantum yield of fluorescence. ${ }^{c}$ Intersystem crossing to the triplet excited state.

All dyes 1-3 can exist in four acid-base forms in aqueous solutions (Scheme 1), and their populations are $\mathrm{pH}$ dependent. At physiologically relevant $\mathrm{pH}(6-8)$, only anionic forms $\mathbf{X}-\mathrm{H}^{-}$ and $\mathbf{X}^{2-}(\mathbf{X}=\mathbf{1}-\mathbf{3})$ are detected (e.g., $\mathrm{p} K_{\mathrm{a}}\left(\mathbf{1}-\mathrm{H}_{2}\right)=4.31$ and $\left.\mathrm{p} K_{\mathrm{a}}\left(\mathbf{1}-\mathrm{H}^{-}\right)=6.43\right),{ }^{70}$ thus, the dianion is the major or sole form of $\mathbf{1}$ at $\mathrm{pH}=7.4$. In contrast, $\mathbf{X}-\mathrm{H}_{2}$ as a neutral species is the major form in non-polar media. The $\mathbf{X}-\mathrm{H}_{3}{ }^{+}$and $\mathbf{X} \mathrm{H}_{2}$ forms are weakly absorbing species in an aqueous environment. ${ }^{70}$

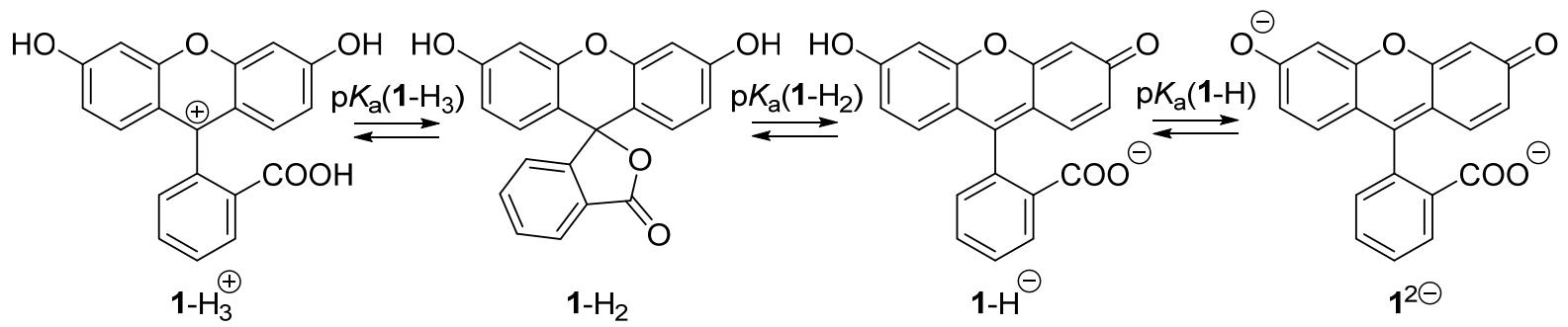

Scheme 1. Acid and base forms of $\mathbf{1}$ in aqueous media. Both anion $1-\mathrm{H}^{-}$and neutral form $\mathbf{1}-\mathrm{H}_{2}$ could be present as more than one tautomer ${ }^{70}$ (omitted for clarity).

Photochemistry and Reactions with Singlet Oxygen. Solutions of 1-3 $\left(c \sim 1.3-1.5 \times 10^{-5}\right.$ mol dm${ }^{-3}, V=3 \mathrm{~mL}$ ) in PBS buffer or methanol at $21{ }^{\circ} \mathrm{C}$ in a quartz cuvette were irradiated with LED sources $\left(\lambda_{\text {irr }}=400-700 \mathrm{~nm}\right.$; Table S6), and the absorption spectra were recorded in the corresponding time intervals until no starting material was observed. The first-order degradation rate constants were obtained from the single-exponential fit of the dye's decay monitored at its absorption maximum (Table S1). Comparison of the observed rate constants (corrected to the amount of light absorbed; Table S1), calculated from a decrease of the absorption signals of the starting material (no other major peaks appeared in the absorption spectrum during irradiation), allowed us to calculate relative quantum yields of degradation 
(Table S2). We found that both $\mathbf{2}$ and $\mathbf{3}$ undegro degradation with similar quantum yields, which are about 5 -fold lower in comparison with degradation of $\mathbf{1}$.

To test the reactivity of the dyes with singlet oxygen, thermostated solutions $\left(T=40^{\circ} \mathrm{C}\right)$ of 1 3 in methanol containing 1,4-dimethyl-1,4-dihydro-1,4-epidioxynaphthalene ${ }^{77}\left(4, c=5.3 \times 10^{-}\right.$ ${ }^{3} \mathrm{~mol} \mathrm{dm}^{-3}$ ) as a singlet oxygen-generating molecule ${ }^{78}$ were monitored using UV-vis absorption spectroscopy during $20 \mathrm{~h}$ (Supporting Information). The estimated amount of ${ }^{1} \mathrm{O}_{2}$ released from the endoperoxide corresponded to $\sim 30$ equivalents (conservative estimate, $\sim 100$ eq of 4 was used). Because we observed only an insignificant decrease in the concentrations $(<7 \%)$ of all dyes (evaluated at $\lambda_{\text {abs }}$ (max); Figure S5), we conclude that singlet oxygen plays a minor role during the photolysis of 1-3. The dyes in identical aerated aqueous and methanol solutions were completely degraded upon irradiation within the same time frame, although they are known to act as oxygen sensitizers (with $\Phi_{\Delta}=0.03$ for 1 to 0.76 for 3 ; Table 1 ). ${ }^{79}$ Because ${ }^{1} \mathrm{O}_{2}$ has been reported to accelerate dyes' degradation such as $3{ }^{65}$ its role as an oxidant is presumably important only in later degradation steps.

Gaseous Photoproducts. Solutions of 1-3 $\left(c \sim 1-3 \times 10^{-5} \mathrm{~mol} \mathrm{dm}^{-3}, V=0.5 \mathrm{~L}\right)$ in an aqueous triethylammonium acetate (TEAA) buffer solution $\left(c(\right.$ TEAA $)=0.1 \mathrm{~mol} \mathrm{dm}^{-3}, \mathrm{pH}=7.0, I=0.1$ mol dm$\left.)^{-3}\right)$ in a custom-made glass reactor $\left(V_{\text {tot }}=1.05 \mathrm{~L}\right.$; Figure S79) were irradiated with whitelight LED reflectors $\left(\lambda_{\text {irr }}=400-700 \mathrm{~nm}, 3 \times 100 \mathrm{~W}\right.$, Figure S81) for $48 \mathrm{~h}$ under ambient atmosphere. The reaction progress was monitored spectrophotometrically. The headspace above the reaction mixture was transferred into a gas-IR cuvette, and the IR spectra were recorded (Figures 3, S27 and 28; see SI for further details). A well-resolved absorption band with a fine structure was found in the region of 2,220-2,060 $\mathrm{cm}^{-1}$. The spectral features of this band match those of the CO standard (a 10-ppm mixture in dry $\mathrm{N}_{2}(\mathrm{~g})$ ) measured independently under the same conditions (Figure S26). The remaining signals in the IR spectrum were attributed to gases of ambient air (carbon dioxide, water vapor, etc.) or vapors of the buffer constituents. No other gaseous photoproducts in significant amounts were produced from the irradiated solutions. We also tried to estimate the quantity of released $\mathrm{CO}$ by IR spectroscopy. Unfortunately, because of a large $(>100 \%)$ measurement error, we could not determine the CO yield, and the method was used only for the qualitative analysis. 


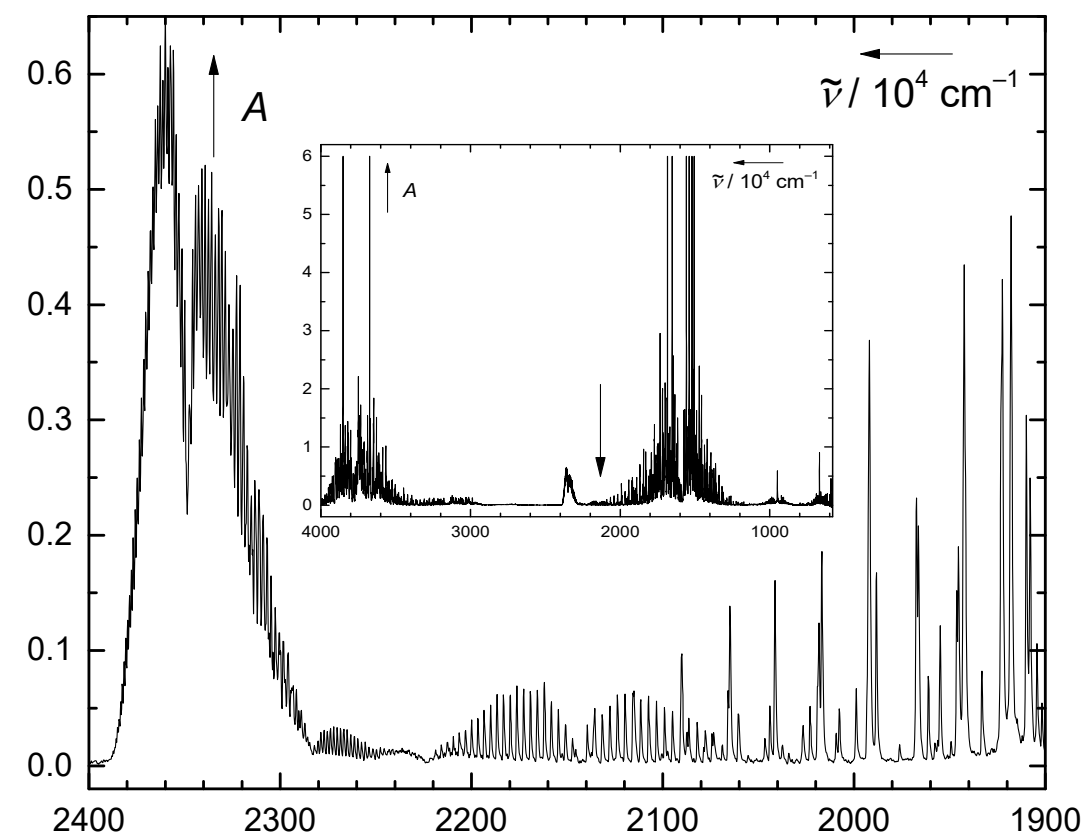

Figure 3. IR spectrum of headspace collected above the reaction mixture after $48 \mathrm{~h}$ irradiation of $\mathbf{3}\left(c=2 \times 10^{-5} \mathrm{~mol} \mathrm{dm}^{-3}\right)$ in an aerated aqueous solution (TEAA buffer, $c$ (TEAA) $=0.1 \mathrm{~mol}$ $\mathrm{dm}^{-3}, \mathrm{pH}=7.0, I=0.1 \mathrm{~mol} \mathrm{dm}{ }^{-3} ; \lambda_{\text {irr }}=400-700 \mathrm{~nm}$; Figure S81). Inset: the full spectrum (arrow, as a visual guide, points at the center of the CO signal at $\sim 2143 \mathrm{~cm}^{-1}$ ).

To quantify the CO amounts, solutions of $1-3\left(c \sim 1.5 \times 10^{-5} \mathrm{~mol} \mathrm{dm}^{-3}\right)$ in PBS were irradiated by white light ( $\lambda_{\text {irr }}=400-700 \mathrm{~nm}, 3 \mathrm{~W}$ LED, Figure S82) in headspace vials $(V=1.5 \mathrm{~mL})$ for $16 \mathrm{~h}$ (until no starting material was observed spectrophotometrically). The amount of CO released into the vial headspace was measured by GC equipped with a reducing gas analyzer (RGA). The molar amounts $n(\mathrm{CO})$ were calculated from the calibration curves (constructed with a standard 10-ppm $\mathrm{CO}$ mixture in $\mathrm{N}_{2}$ ) and compared to the starting molar amounts of a xanthene dye in the sample (Table 2).

Table 2. Yields of released CO $(\mathrm{g})$ determined by gas chromatography. ${ }^{a}$

\begin{tabular}{|l|l|}
\hline Compound & {$[\mathrm{CO}] / \mathrm{eq}$} \\
\hline $\mathbf{1}$ & $0.41 \pm 0.11^{b}\left(0.39 \pm 0.13^{c} ; 0.11 \pm 0.04^{d}\right)$ \\
\hline $\mathbf{2}$ & $1.04 \pm 0.16^{b}\left(0.52 \pm 0.07^{c}\right)$ \\
\hline $\mathbf{3}$ & $0.81 \pm 0.16^{b}\left(0.43 \pm 0.06^{c}\right)$ \\
\hline
\end{tabular}

${ }_{a}$ The aliquots were taken from the headspace after no starting material was observed spectrophotometrically (UV/vis absorption; see Supporting Information). All reaction mixtures were kept under aerated conditions unless stated otherwise. Each experiment was run in triplicate or more replications, and the averaged values are shown. ${ }^{b}$ Irradiation of diluted $(c \sim$ $1.5 \times 10^{-5} \mathrm{~mol} \mathrm{dm}^{-3}$ ) solutions; the detection by a reducing gas analyzer (RGA). Irradiation of more concentrated $\left(c \sim 1-3 \times 10^{-4} \mathrm{~mol} \mathrm{dm}^{-3}\right){ }^{c}$ aerated and ${ }^{d}$ argon-bubbled solutions; the detection was done by a mass spectrometer (MS). 
We also investigated the effect of the initial dye concentration on the $\mathrm{CO}$ release yields. More concentrated aerated PBS solutions of 1-3 $\left(c \sim 1 \times 10^{-4} \mathrm{~mol} \mathrm{dm}^{-3} ; V=0.5 \mathrm{~mL}\right)$ were irradiated with white-light LED reflectors $\left(\lambda_{\text {irr }}=400-700 \mathrm{~nm}, 3 \times 100 \mathrm{~W}\right.$ reflector; Figure S81), until no starting material was observed. The headspace was analyzed by GC-MS (Table 2; see Supporting Information). While the chemical yields of released $\mathrm{CO}$ from 1 were found independent of the dye concentration in the range from $1 \times 10^{-5}$ to $1 \times 10^{-4} \mathrm{~mol} \mathrm{dm}^{-3}$, we found that the yields from irradiated compounds $\mathbf{2}$ and $\mathbf{3}$ decreased in more concentrated solutions by a factor of $\sim 2$. Indeed, rose bengal photochemistry has been demonstrated to be a concentrationdependent process. ${ }^{65} \mathrm{We}$ hypothesized that this effect is connected to competitive bimolecular (nonproductive) processes that are more efficient at higher concentrations than the $\mathrm{CO}$ liberation, especially for triplet-excited compounds. Dyes with high intersystem quantum efficiency, such as $3\left(\Phi_{\text {isc }}=0.98\right.$ in PBS) ${ }^{80}$ readily transfer excitation energy to oxygen in the solution to produce singlet oxygen, which may significantly contribute to its decomposition (bleaching). ${ }^{65}$

We found that oxygen $\left(\mathrm{O}_{2}\right)$ plays an indispensable role in the complex photochemistry of dyes 1-3. CO release was about 2.5 -fold lower in samples of $\mathbf{1}$ deoxygenated by argon purging (Table 2), suggesting that the absence of oxygen does not completely stop the CO production. Oxygen was found to play only a minor role in the photochemical transformations of dyes with a small quantum yield of intersystem crossing, such as in $\mathbf{1}\left(\Phi_{\text {isc }} \sim 0.03-0.06\right) .{ }^{79,81}$ Upon prolonged irradiation of 1 in an oxygen-free environment, no ${ }^{10}$ or only very small ${ }^{9}$ irreversible changes have been observed. However, the photodecomposition of fluorescein was observed in the presence of oxygen ${ }^{9}$ or other oxidizing agents.

We attempted to find out which carbon atom of fluorescein is primarily responsible for $\mathrm{CO}$ formation. We prepared fluorescein 1 labeled with a ${ }^{13} \mathrm{C}$ isotope (see SI for details on the synthesis). A solution of ${ }^{13} \mathrm{C}_{2}-1$ (containing $~ 50 \%$ of ${ }^{13} \mathrm{C}$ in the carboxylic group and $\sim 50 \%$ of ${ }^{13} \mathrm{C}$ in the $\mathrm{C}-9$ atom, Figure 5) was irradiated under the same conditions as described above and analyzed by GC-MS. The formation of the labeled ${ }^{13} \mathrm{CO}$ was indeed observed, although only in the total $\sim 5 \%$ amount (Figure S83). We conclude that the origin of this isotope in CO from decarbonylation of the carboxylate group or oxidation of the C-9 atom is associated with minor pathways only (the upper limit of this enrichment is below 10\%).

Non-gaseous Photoproducts. We used various analytical techniques to analyze photolyzed mixtures at different reaction conversions to identify other products of the photochemical degradation of 1-3. Solutions of $\mathbf{1},{ }^{13} \mathrm{C}_{2}-\mathbf{1}, \mathbf{2}$, or $3\left(c \sim 6 \times 10^{-3} \mathrm{~mol} \mathrm{dm}^{-3}\right)$ in $\mathrm{D}_{2} \mathrm{O}$-based PBS were irradiated with white-light LED $\left(\lambda_{\text {irr }}=400-700 \mathrm{~nm}, 3 \times 100 \mathrm{~W}\right.$, Figure S81) until no starting material was observed, and the reaction mixtures were analyzed by NMR. Upon irradiation of $1,{ }^{13} \mathrm{C}_{2}-1$ or 2 , we observed a relatively simple set of signals in both aromatic and aliphatic regions of ${ }^{1} \mathrm{H} \mathrm{NMR}$, with a distinct multiplet in the $\delta=7.5-7.7 \mathrm{ppm}$ region and a singlet at $\delta$ $\sim 8.4$ ppm (Figures S37, S39 and S41). However, ${ }^{13} \mathrm{C}\left\{{ }^{1} \mathrm{H}\right\}$ NMR revealed only one major signal at $\delta 169.2 \mathrm{ppm}$, which we assigned to phthalic acid (Figure S32). This indicated that if other compounds possessing the ${ }^{13} \mathrm{C}$ carbon atom are present, their concentrations must be very low. Further NMR (including 2D) experiments and MS analyses (Figures S36) allowed us to identify that the major signal belongs to phthalic acid formed in $\sim 95 \%$ yield at the $\sim 30 \%$ conversion of 2 (Figure 4). The singlet at $\delta \sim 8.4 \mathrm{ppm}$ was attributed to formic acid using an authentic sample. A rather complicated set of signals, especially in the aromatic region, with a broad cluster of signals at $\delta=7.5-8.0 \mathrm{ppm}$ (Figures S30, S31, S38 and S39) was observed. However, no other photoproducts have been identified. Upon exhaustive irradiation of 1 and ${ }^{13} \mathrm{C}_{2}-1$ in $\mathrm{CD}_{3} \mathrm{OD}$, we found a similar product distribution, that is, formic acid (Figure S34) and phthalic acid (and also from ${ }^{13} \mathrm{C}_{2}-1$; singlet at $\delta=173.7 \mathrm{ppm}$ in ${ }^{13} \mathrm{C}\left\{{ }^{1} \mathrm{H}\right\}$ NMR; Figure S35). For 3 in PBS, we observed the corresponding signal at $\delta \sim 8.4 \mathrm{ppm}$, which was also assigned to formic acid 
(Figure S44). We assumed that analogous tetrachlorophthalic acid could be produced from 3, but we found no evidence of its formation under the given conditions.

The photoproduct distribution was not constant during the photolysis of 1-3 ( ${ }^{1} \mathrm{H}$ NMR; (Figures S37, S41 and S43). Phthalic acid emerged at an early stage of irradiation in high yields (up to $\sim 95 \%$ at $\sim 30 \%$ conversion of 2 ; Figure 4 ) and slowly degraded upon prolonged irradiation. On the other hand, formic acid appeared later in the course of the reaction. We assume that both compounds must be products of secondary photochemical processes (Figure 5), as there is no elementary step that could lead to their formation.

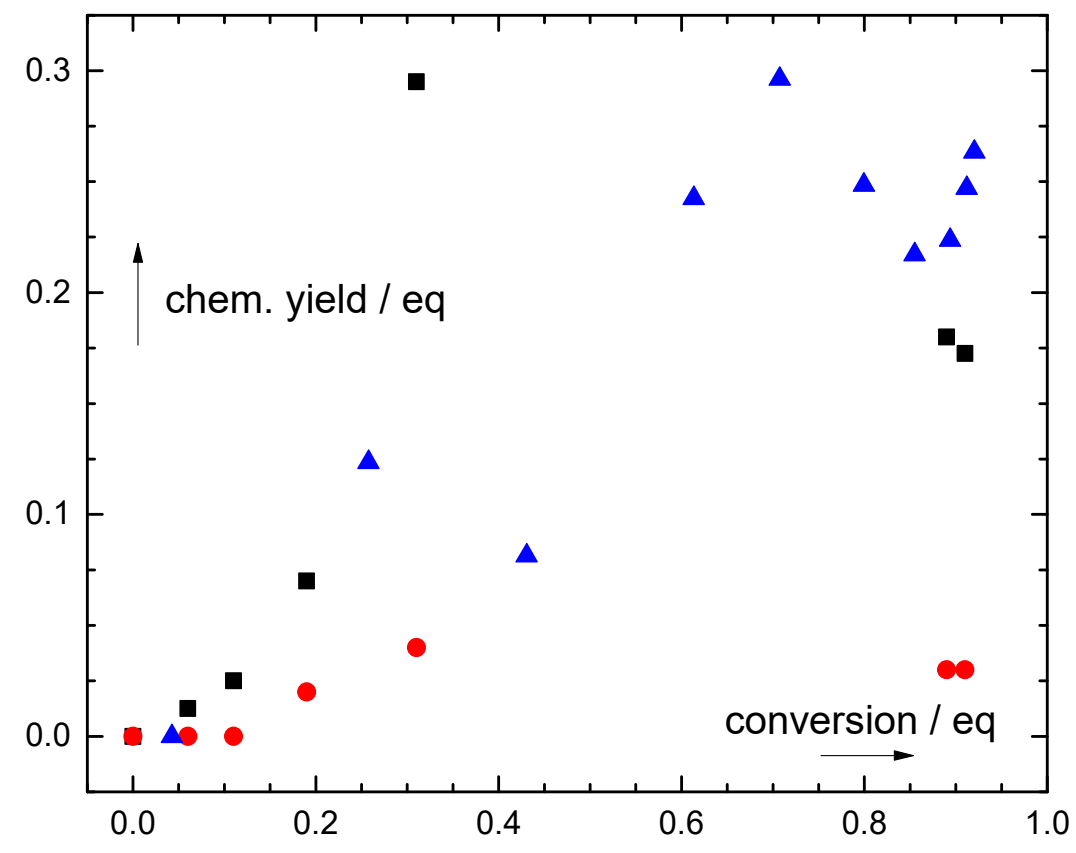

Figure 4. Dependence of the chemical yields of phthalic acid (black squares), formic acid (red circles, and CO (blue triangles) on the photodegradation of 2 . Concentrations photoproducts were determined in independent experiments, and in the case of phthalic and formic acids, they were measured by ${ }^{1} \mathrm{H}$ NMR and the concentrations of CO by GC-MS (Supporting Information).

Next, an array of solutions of $\mathbf{1}$ and ${ }^{13} \mathrm{C}_{2}-\mathbf{1}\left(c \sim 3 \times 10^{-5} \mathrm{~mol} \mathrm{dm}{ }^{-3}, V=0.5 \mathrm{~mL}\right)$ in aerated and degassed PBS were irradiated in parallel (white-light LED reflectors, Figure S81) until no starting material was observed by UV-vis spectroscopy ( $\sim$ days). The LC-MS analyses (Figures S47-S68, for details on this analysis, see Supporting Information) identified phthalic acid (Figures S58 and S63) as a photoproduct in accordance with our NMR experiments. Several other relatively intense signals appeared, and we attempted to assess the structures based on the corresponding MS spectra. We considered several different modes of bonds' disconnections in $\mathbf{1}$ and suggested potential structures derived from the xanthene tricyclic core (for example, Figure S7), such as various diphenylethers, carboxylic acids, phenol derivatives, quinones, or polyphenols. None of the observed $\mathrm{m} / \mathrm{z}$ signals corresponded with the exact structures of the proposed products (Supporting Information), but suggests low-mass products with very similar structures. In addition, anticipated diphenyletheres and phenols are likely to undergo efficient secondary photochemical degradation. For example, phenol can readily be oxidized by singlet oxygen to give quinones. ${ }^{82}$ Such subsequent photochemical reactions 
hamper their identification. The quantum yield of ${ }^{1} \mathrm{O}_{2}$ production sensitized by $\mathbf{1}$ is low ( $\Phi_{\text {isc }}$ $<0.06$, see above).

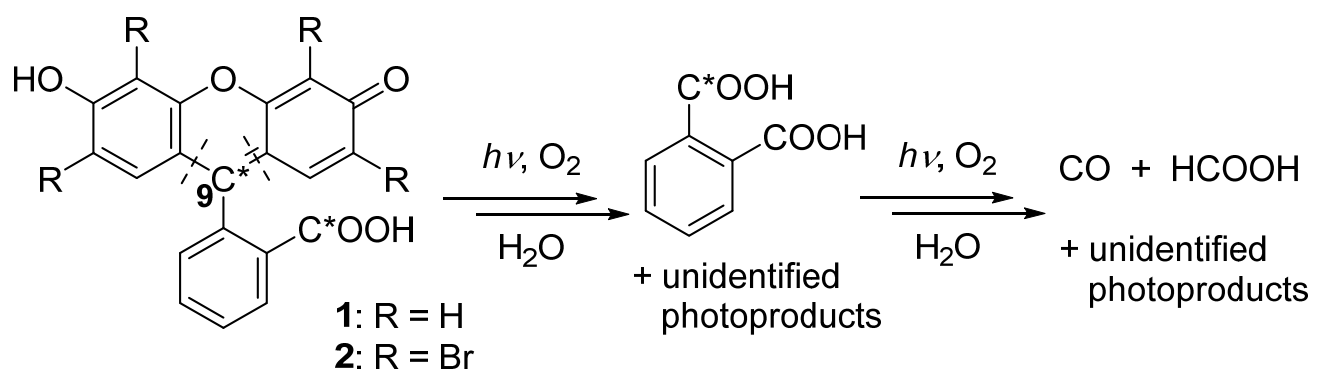

Figure 5. Photochemistry of $\mathbf{1},{ }^{13} \mathrm{C}_{2}-\mathbf{1}$ and $\mathbf{2}$ in PBS. The products were identified by NMR and EI-MS. Note: * denotes the ${ }^{13} \mathrm{C}$ label (only one of two positions in $\mathbf{1}$ is labeled in particular molecule). Dashed lines show disconnection leading to a multistep oxidative release of phthalic acid.

If ${ }^{13} \mathrm{C}_{2}-1$ was photolyzed to give labeled phthalic acid but not $\mathrm{CO}$ or $\mathrm{HCOOH}$ to a more significant extent, these compounds must preferentially originate from other parts of the molecule than the C9 atom and the carboxylic group. Still, the major degradation pathway involves the central $2 \mathrm{H}$-pyran ring opening. Released $\mathrm{CO}$ contained only about $<5 \%$ of ${ }^{13} \mathrm{C}$ (Figure S83), which also indicated degradation of the remaining aromatic ring(s). Released formic acid also contained $<5 \%$ of the ${ }^{13} \mathrm{C}$. The ring opening reactions are most likely oxidative processes, involving either singlet oxygen sensitized by the triplet excited dye molecules (but at one of the subsequent reaction steps discussed above) or ground-state oxygen that reacts with excited or radical species. Nevertheless, a $<5 \%$ content of ${ }^{13} \mathrm{C}$ in $\mathrm{CO}$ suggests that both labeled carbons still partially contribute to its formation.

We also evaluated the photochemical reactivity of fluorescein in the gas phase using photodissociation and mass spectroscopies. From all acid-base forms, only a cation (which is not present in aqueous media under physiological $\mathrm{pH}$ but requires a significantly more acidic environment; Scheme 1) was detectable. We found that photodissociation spectra of $\mathbf{1}^{+}$feature a low-intensity absorption maximum at $\lambda_{\text {obs }}=420.8 \mathrm{~nm}$ that corresponds to the $0-0$ transition (Figure S8). A helium-tagging spectrum suggested that the nature of the excited state is most likely rather complicated (see Supporting Information for more details).

Mass spectroscopy data further showed that the excited fluorescein cation $\mathbf{1}^{+}$undergoes several fragmentations, such as the loss of 46 mass units (Figure S9), which could correspond to the dissociation of formic acid from the carboxylate moiety (see Supporting Information for more details). However, we were unable to draw more detailed conclusions or establish structures of other putative photoproducts. Unfortunately, our experimental setup hindered our attempts to examine fluorescein anions, $\mathbf{1}-\mathrm{H}^{-}$and $\mathbf{1}^{2-}$ (Scheme 1).

Finally, we studied the thermal decomposition of 1-3 to rule out possible dark decarbonylation. No release of $\mathrm{CO}$ was observed upon heating up to $500{ }^{\circ} \mathrm{C}$. We identified only $\mathrm{CO}_{2}$ and $\mathrm{H}_{2} \mathrm{O}$ as the major gaseous products (Figures S45-S56).

\section{Conclusions}

In this work, we demonstrate that extensive irradiation of common organic dyes, fluorescein, eosin Y, and rose bengal, with green and white visible light leads to the release of carbon monoxide in biologically relevant yields. ${ }^{64}$ The release of $\mathrm{CO}$ was evidenced and quantified by independent analytical methods, such as optical spectroscopy, chromatography and mass 
spectroscopy techniques. In addition, ${ }^{13} \mathrm{C}$ isotopic labeling was utilized to identify the origin of $\mathrm{CO}$ formation. The isotopic distribution of the ${ }^{13} \mathrm{C}$ carbon in $\mathrm{CO}$ suggests that there are at least two individual processes for its formation. We also found that phthalic and formic acids are produced as other non-gaseous photoproducts. We cannot draw a plausible detailed mechanism of the observed phototransformations of the studied dyes at the moment, but we conclude that the main pathway to the release of $\mathrm{CO}$ and the other photoproducts is a complex multistep reaction that involves multiple excitation and several oxidative degradation steps. Our data suggest that the photochemical degradation and production of $\mathrm{CO}$ from these dyes may be of biological importance that should be considered in medicinal applications.

\section{Associated Content}

Materials and methods, synthetic details, photophysical properties of fluorophores, details on analytical methods, MS, NMR, UV/vis, fluorescence spectra, solubility of CO, stability determination experiments, details on thermogravimetric analyses, photodisociation spectroscopy.

\section{Author Information}

*E-mail: sebej@recetox.muni.cz

\section{Acknowledgment}

This work was supported by the Czech Science Foundation (P. S.: GJ20-30004Y), the CETOCOEN EXCELLENCE Teaming 2 project (supported by the Czech Ministry of Education, Youth and Sports: CZ.02.1.01/0.0/0.0/17_043/0009632 and EU H2020: 857560) and the RECETOX research infrastructure (LM2018121), grant GAUK 31462 given by Charles University, and the financial support of the Ministry of Transport within the programme of long-term conceptual development of research institutions. The authors express their thanks to Lukáš Maier and Miroslava Bittová for their help with the NMR and mass spectrometry measurements, Dominik Madea (all from Masaryk University, Brno) for the synthesis of 1,4dimethyl-1,4-dihydro-1,4-epidioxynaphthalene, Tomáš Slanina (IOCB, Prague) for an MS analysis of the product mixtures and fruitful discussions. We thank Jana Roithová (Radboud University, Nijmegen) for an access to equippment for measurement of photodisociation and helium-tagging spectroscopy. Robert Vícha (T. Bata University, Zlín) is acknowledged for elemental analyses, Zdeněk Moravec for his assistance with thermogravimetry, Luboš Jílek for his assistance with light sources, Jiří Nečas for manufacturing custom glass reactors, and Jiří Kalina (all from Masaryk University, Brno) for statistical analysis of the data.

\section{References}

(1) Lavis, L. D. Chemistry Is Dead. Long Live Chemistry! Biochemistry 2017, 56 (39), 5165-5170. https://doi.org/10.1021/acs.biochem.7b00529.

(2) Wagh, S. B.; Maslivets, V. A.; La Clair, J. J.; Kornienko, A. Lessons in Organic Fluorescent Probe Discovery. ChemBioChem 2021, 22 (22), 3109-3139.

(3) Yamashita, M.; Kashiwagi, H. Photodegradation Mechanisms in Laser Dyes: A Laser Irradiated ESR Study. IEEE Journal of Quantum Electronics 1976, 12 (2), 90-95. https://doi.org/10.1109/JQE.1976.1069096.

(4) Han, J.; Burgess, K. Fluorescent Indicators for Intracellular PH. Chem. Rev. 2010, 110 (5), 2709-2728. https://doi.org/10.1021/cr900249z.

(5) Lakowicz, J. R. Principles of Fluorescence Spectroscopy, 3rd ed.; Springer US, 2006. 
(6) Boudin, S. Phosphorescence des solutions glycériques d'éosine influence des iodures. $J$. Chim. Phys. 1930, 27, 285-290. https://doi.org/10.1051/jcp/1930270285.

(7) Grossweiner, L. I.; Zwicker, E. F. Primary Processes in the Photochemistry of Eosin. $J$. Chem. Phys. 1959, 31 (4), 1141-1142. https://doi.org/10.1063/1.1730532.

(8) Uchida, K.; Kato, S.; Koizumi, M. Reductive Photo-Bleaching of Eosine: Effect of Added Substances on the Rate of Reductive Photo-Bleaching. Nature 1959, 184 (4699), 1620-1621. https://doi.org/10.1038/1841620b0.

(9) Lindqvist, L. A Flash Photolysis Study of Fluorescein. Arkiv för kemi 1960, 16 (8), 79137.

(10) Imamura, M.; Koizumi, M. Irreversible Photobleaching of the Solution of Fluorescent Dyes. I. Kinetic Studies on the Primary Process. BCSJ 1955, 28 (2), 117-124. https://doi.org/10.1246/bcsj.28.117.

(11) Sebej, P.; Slanina, T. Visible-Light Activated PhotoCORMs: Rational Design of COReleasing Organic Molecules Absorbing in the Tissue-Transparent Window. Photochem. Photobiol. Sci. 2018. https://doi.org/10.1039/C8PP00096D.

(12) Givens, R. S. Photoextrusion of Small Molecules. In Organic Photochemistry; Padwa, A., Ed.; Marcel Dekker, 1981; pp 227-346.

(13) Norrish, R. G. W.; Bamford, C. H. Photo-Decomposition of Aldehydes and Ketones. Nature 1937, 140 (3535), 195-196. https://doi.org/10.1038/140195b0.

(14) Antony, L. A. P.; Slanina, T.; Šebej, P.; Šolomek, T.; Klán, P. Fluorescein Analogue Xanthene-9-Carboxylic Acid: A Transition-Metal-Free CO Releasing Molecule Activated by Green Light. Org. Lett. 2013, 15 (17), 4552-4555. https://doi.org/10.1021/o14021089.

(15) Martínek, M.; Váňa, J.; Šebej, P.; Navrátil, R.; Slanina, T.; Ludvíková, L.; Roithová, J.; Klán, P. Photochemistry of a 9-Dithianyl-Pyronin Derivative: A Cornucopia of Reaction Intermediates Lead to Common Photoproducts. ChemPlusChem 2020, n/a (n/a). https://doi.org/10.1002/cplu.202000370.

(16) Untereiner, A. A.; Wu, L.; Wang, R. The Role of Carbon Monoxide as a Gasotransmitter in Cardiovascular and Metabolic Regulation. In Gasotransmitters: Physiology and Pathophysiology; Springer, Berlin, Heidelberg, 2012; pp 37-70. https://doi.org/10.1007/978-3-642-30338-8_2.

(17) Chim, N.; Johnson, P. M.; Goulding, C. W. Insights into Redox Sensing Metalloproteins in Mycobacterium Tuberculosis. Journal of Inorganic Biochemistry 2014, 133, 118-126. https://doi.org/10.1016/j.jinorgbio.2013.11.003.

(18) Pitcher, R. S.; Brittain, T.; Watmough, N. J. Complex Interactions of Carbon Monoxide with Reduced Cytochrome Cbb3 Oxidase from Pseudomonas Stutzeri. Biochemistry 2003, 42 (38), 11263-11271. https://doi.org/10.1021/bi0343469.

(19) Wu, L.; Wang, R. Carbon Monoxide: Endogenous Production, Physiological Functions, and Pharmacological Applications. Pharmacol Rev 2005, 57 (4), 585-630. https://doi.org/10.1124/pr.57.4.3.

(20) Motterlini, R.; Otterbein, L. E. The Therapeutic Potential of Carbon Monoxide. Nature Reviews Drug Discovery 2010, 9 (9), 728. https://doi.org/10.1038/nrd3228.

(21) Lowson, S. M. Alternatives to Nitric Oxide. Br Med Bull 2004, 70 (1), 119-131. https://doi.org/10.1093/bmb/ldh028.

(22) Nguyen, D.; Nguyen, T.-K.; Rice, S. A.; Boyer, C. CO-Releasing Polymers Exert Antimicrobial Activity. Biomacromolecules 2015, 16 (9), 2776-2786. https://doi.org/10.1021/acs.biomac.5b00716.

(23) Motterlini, R.; Haas, B.; Foresti, R. Emerging Concepts on the Anti-Inflammatory Actions of Carbon Monoxide-Releasing Molecules (CO-RMs). Med Gas Res 2012, 2 , 28. https://doi.org/10.1186/2045-9912-2-28. 
(24) Otterbein, L. E.; Bach, F. H.; Alam, J.; Soares, M.; Lu, H. T.; Wysk, M.; Davis, R. J.; Flavell, R. A.; Choi, A. M. K. Carbon Monoxide Has Anti-Inflammatory Effects Involving the Mitogen-Activated Protein Kinase Pathway. Nat Med 2000, 6 (4), 422 428. https://doi.org/10.1038/74680.

(25) Otterbein, L. E.; Otterbein, S. L.; Ifedigbo, E.; Liu, F.; Morse, D. E.; Fearns, C.; Ulevitch, R. J.; Knickelbein, R.; Flavell, R. A.; Choi, A. M. MKK3 Mitogen-Activated Protein Kinase Pathway Mediates Carbon Monoxide-Induced Protection Against Oxidant-Induced Lung Injury. The American Journal of Pathology 2003, 163 (6), 25552563. https://doi.org/10.1016/S0002-9440(10)63610-3.

(26) Halilovic, A.; Patil, K. A.; Bellner, L.; Marrazzo, G.; Castellano, K.; Cullaro, G.; Dunn, M. W.; Schwartzman, M. L. Knockdown of Heme Oxygenase-2 Impairs Corneal Epithelial Cell Wound Healing. J. Cell. Physiol. 2011, 226 (7), 1732-1740. https://doi.org/10.1002/jcp.22502.

(27) Campbell, J. A. The Effect of Carbon Monoxide and Other Agents upon the Rate of Tumour Growth. J. Pathol. 1932, 35 (3), 379-394. https://doi.org/10.1002/path.1700350309.

(28) Vítek, L.; Gbelcová, H.; Muchová, L.; Váňová, K.; Zelenka, J.; Koníčková, R.; Suk, J.; Zadinova, M.; Knejzlík, Z.; Ahmad, S.; Fujisawa, T.; Ahmed, A.; Ruml, T. Antiproliferative Effects of Carbon Monoxide on Pancreatic Cancer. Dig Liver Dis 2014, 46 (4), 369-375. https://doi.org/10.1016/j.dld.2013.12.007.

(29) Allanson, M.; Reeve, V. E. Carbon Monoxide Signalling Reduces Photocarcinogenesis in the Hairless Mouse. Cancer Immunol Immunother 2007, 56 (11), 1807-1815. https://doi.org/10.1007/s00262-007-0324-1.

(30) Yang, X.; de Caestecker, M.; Otterbein, L. E.; Wang, B. Carbon Monoxide: An Emerging Therapy for Acute Kidney Injury. Medicinal Research Reviews 2019, 40 (4), 1147-1177. https://doi.org/10.1002/med.21650.

(31) Kourembanas, S. Hypoxia and Carbon Monoxide in the Vasculature. Antioxid. Redox Signal. 2002, 4 (2), 291-299. https://doi.org/10.1089/152308602753666343.

(32) Blumenthal, I. Carbon Monoxide Poisoning. J R Soc Med 2001, 94 (6), 270-272.

(33) Motterlini, R.; Otterbein, L. E. The Therapeutic Potential of Carbon Monoxide. Nature Reviews Drug Discovery 2010, 9 (9), 728. https://doi.org/10.1038/nrd3228.

(34) Gullotta, F.; Masi, A. di; Ascenzi, P. Carbon Monoxide: An Unusual Drug. IUBMB Life 2012, 64 (5), 378-386. https://doi.org/10.1002/iub.1015.

(35) Adach, W.; Olas, B. Carbon Monoxide and Its Donors - Their Implications for Medicine. Future Medicinal Chemistry 2018, 11 (1), 61-73. https://doi.org/10.4155/fmc2018-0215.

(36) Romão, C. C.; Blättler, W. A.; Seixas, J. D.; Bernardes, G. J. L. Developing Drug Molecules for Therapy with Carbon Monoxide. Chem. Soc. Rev. 2012, 41 (9), 35713583. https://doi.org/10.1039/C2CS15317C.

(37) Heinemann, S. H.; Hoshi, T.; Westerhausen, M.; Schiller, A. Carbon Monoxide Physiology, Detection and Controlled Release. Chem. Commun. 2014, 50 (28), 3644 3660. https://doi.org/10.1039/C3CC49196J.

(38) Wrighton, M. Photochemistry of Metal Carbonyls. Chem. Rev. 1974, 74 (4), 401-430. https://doi.org/10.1021/cr60290a001.

(39) Wright, M. A.; Wright, J. A. PhotoCORMs: CO Release Moves into the Visible. Dalton Trans. 2016, 45 (16), 6801-6811. https://doi.org/10.1039/C5DT04849D.

(40) Peterson, J. A.; Wijesooriya, C.; Gehrmann, E. J.; Mahoney, K. M.; Goswami, P. P.; Albright, T. R.; Syed, A.; Dutton, A. S.; Smith, E. A.; Winter, A. H. Family of BODIPY Photocages Cleaved by Single Photons of Visible/Near-Infrared Light. J. Am. Chem. Soc. 2018, 140 (23), 7343-7346. https://doi.org/10.1021/jacs.8b04040. 
(41) Popova, M.; Soboleva, T.; Ayad, S.; Benninghoff, A. D.; Berreau, L. M. A Visible Light-Activated Quinolone Carbon Monoxide-Releasing Molecule: Prodrug and Albumin-Assisted Delivery Enable Anti-Cancer and Potent Anti-Inflammatory Effects. J. Am. Chem. Soc. 2018. https://doi.org/10.1021/jacs.8b06011.

(42) Feng, W.; Feng, S.; Feng, G. CO Release with Ratiometric Fluorescence Changes: A Promising Visible-Light-Triggered Metal-Free CO-Releasing Molecule. Chem. Commun. 2019, 55 (61), 8987-8990. https://doi.org/10.1039/C9CC04026A.

(43) Soboleva, T.; Berreau, L. M. 3-Hydroxyflavones and 3-Hydroxy-4-Oxoquinolines as Carbon Monoxide-Releasing Molecules. Molecules 2019, 24 (7). https://doi.org/10.3390/molecules24071252.

(44) Kim, W. B.; Shelley, A. J.; Novice, K.; Joo, J.; Lim, H. W.; Glassman, S. J. DrugInduced Phototoxicity: A Systematic Review. Journal of the American Academy of Dermatology 2018, 79 (6), 1069-1075. https://doi.org/10.1016/j.jaad.2018.06.061.

(45) Hofmann, G. A.; Weber, B. Drug-Induced Photosensitivity: Culprit Drugs, Potential Mechanisms and Clinical Consequences. JDDG: Journal der Deutschen Dermatologischen Gesellschaft 2021, 19 (1), 19-29. https://doi.org/10.1111/ddg.14314.

(46) Cosa, G.; Lukeman, M.; Scaiano, J. C. How Drug Photodegradation Studies Led to the Promise of New Therapies and Some Fundamental Carbanion Reaction Dynamics along the Way. Acc. Chem. Res. 2009, 42 (5), 599-607. https://doi.org/10.1021/ar8001969.

(47) Monteiro, A. F.; Rato, M.; Martins, C. Drug-Induced Photosensitivity: Photoallergic and Phototoxic Reactions. Clinics in Dermatology 2016, 34 (5), 571-581. https://doi.org/10.1016/j.clindermatol.2016.05.006.

(48) Goetze, S.; Hiernickel, C.; Elsner, P. Phototoxicity of Doxycycline: A Systematic Review on Clinical Manifestations, Frequency, Cofactors, and Prevention. SPP 2017, 30 (2), 76-80. https://doi.org/10.1159/000458761.

(49) Naranjo, A.; Arboleda, A.; Martinez, J. D.; Durkee, H.; Aguilar, M. C.; Relhan, N.; Nikpoor, N.; Galor, A.; Dubovy, S. R.; Leblanc, R.; Flynn, H. W.; Miller, D.; Parel, J.M.; Amescua, G. Rose Bengal Photodynamic Antimicrobial Therapy for Patients With Progressive Infectious Keratitis: A Pilot Clinical Study. American Journal of Ophthalmology 2019, 208, 387-396. https://doi.org/10.1016/j.ajo.2019.08.027.

(50) Barton, M. J.; Morley, J. W.; Stoodley, M. A.; Lauto, Antonio.; Mahns, D. A. Nerve Repair: Toward a Sutureless Approach. Neurosurg Rev 2014, 37 (4), 585-595. https://doi.org/10.1007/s10143-014-0559-1.

(51) Alarcon, E. I.; Poblete, H.; Roh, H.; Couture, J.-F.; Comer, J.; Kochevar, I. E. Rose Bengal Binding to Collagen and Tissue Photobonding. ACS Omega 2017, 2 (10), 66466657. https://doi.org/10.1021/acsomega.7b00675.

(52) Baeyer, A. Ueber Eine Neue Klasse von Farbstoffen. Berichte der deutschen chemischen Gesellschaft 1871, 4 (2), 555-558. https://doi.org/10.1002/cber.18710040209.

(53) Majek, M.; Filace, F.; von Wangelin, A. J. On the Mechanism of Photocatalytic Reactions with Eosin Y. Beilstein J Org Chem 2014, 10, 981-989. https://doi.org/10.3762/bjoc.10.97.

(54) Srivastava, V.; Singh, P. P. Eosin Y Catalysed Photoredox Synthesis: A Review. RSC Adv. 2017, 7 (50), 31377-31392. https://doi.org/10.1039/C7RA05444K.

(55) Wilkinson, F.; Helman, W. P.; Ross, A. B. Quantum Yields for the Photosensitized Formation of the Lowest Electronically Excited Singlet State of Molecular Oxygen in Solution. Journal of Physical and Chemical Reference Data 1993, 22 (1), 113-262. https://doi.org/10.1063/1.555934.

(56) DeRosa, M. C.; Crutchley, R. J. Photosensitized Singlet Oxygen and Its Applications. Coordination Chemistry Reviews 2002, 21. 
(57) Brancato, R.; Bandello, F.; Lattanzio, R. Iris Fluorescein Angiography in Clinical Practice. Survey of Ophthalmology 1997, 42 (1), 41-70. https://doi.org/10.1016/S00396257(97)84042-8.

(58) Sonn, G. A.; Jones, S.-N. E.; Tarin, T. V.; Du, C. B.; Mach, K. E.; Jensen, K. C.; Liao, J. C. Optical Biopsy of Human Bladder Neoplasia With In Vivo Confocal Laser Endomicroscopy. The Journal of Urology 2009, 182, 1299-1305. https://doi.org/10.1016/j.juro.2009.06.039.

(59) Wang, L. M.; Banu, M. A.; Canoll, P.; Bruce, J. N. Rationale and Clinical Implications of Fluorescein-Guided Supramarginal Resection in Newly Diagnosed High-Grade Glioma. Frontiers in Oncology 2021, 11.

(60) Persaud, N.; Jiang, M.; Shaikh, R.; Bali, A.; Oronsaye, E.; Woods, H.; Drozdzal, G.; Rajakulasingam, Y.; Maraj, D.; Wadhawan, S.; Umali, N.; Wang, R.; McCall, M.; Aronson, J. K.; Plüddemann, A.; Moja, L.; Magrini, N.; Heneghan, C. Comparison of Essential Medicines Lists in 137 Countries. Bull World Health Organ 2019, 97 (6), 394404C. https://doi.org/10.2471/BLT.18.222448.

(61) World Health Organization Model List of Essential Medicines: 21st List 2019, 21st ed.; 2019.

(62) Schulte, E. K. W.; Wittekind, D. H. Standardized Thionin-Eosin Y: A Quick Stain for Cytology. Stain Technology 1989, 64 (5), 255-256. https://doi.org/10.3109/10520298909107012.

(63) Feenstra, R. P. G.; Tseng, S. C. G. What Is Actually Stained by Rose Bengal? Archives of Ophthalmology 1992, 110 (7), 984-993. https://doi.org/10.1001/archopht.1992.01080190090035.

(64) Šranková, M.; Dvořák, A.; Martínek, M.; Šebej, P.; Klán, P.; Vítek, L.; Muchová, L. Antiproliferative and Cytotoxic Activities of Fluorescein - a Diagnostic Angiography Dye. International Journal of Molecular Sciences 2022, 23, submitted.

(65) Ludvíková, L.; Friš, P.; Heger, D.; Šebej, P.; Wirz, J.; Klán, P. Photochemistry of Rose Bengal in Water and Acetonitrile: A Comprehensive Kinetic Analysis. Phys. Chem. Chem. Phys. 2016, 18 (24), 16266-16273. https://doi.org/10.1039/C6CP01710J.

(66) Cramer, L. E.; Spears, K. G. Hydrogen Bond Strengths from Solvent-Dependent Lifetimes of Rose Bengal Dye. J. Am. Chem. Soc. 1978, 100 (1), 221-227. https://doi.org/10.1021/ja00469a039.

(67) Fleming, G. R.; Knight, A. W. E.; Morris, J. M.; Morrison, R. J. S.; Robinson, G. W. Picosecond Fluorescence Studies of Xanthene Dyes. J. Am. Chem. Soc. 1977, 99 (13), 4306-4311. https://doi.org/10.1021/ja00455a017.

(68) Rauf, M. A.; Graham, J. P.; Bukallah, S. B.; Al-Saedi, M. A. S. Solvatochromic Behavior on the Absorption and Fluorescence Spectra of Rose Bengal Dye in Various Solvents. Spectrochimica Acta Part A: Molecular and Biomolecular Spectroscopy 2009, 72 (1), 133-137. https://doi.org/10.1016/j.saa.2008.08.018.

(69) Molecular Probes Handbook, A Guide to Fluorescent Probes and Labeling Technologies, 11th Edition, 11th edition.; Johnson, I., Spence, M. T. Z., Eds.; Life Technologies: Carlsbad, Calif., 2010.

(70) Sjöback, R.; Nygren, J.; Kubista, M. Absorption and Fluorescence Properties of Fluorescein. Spectrochimica Acta Part A: Molecular and Biomolecular Spectroscopy 1995, 51 (6), L7-L21. https://doi.org/10.1016/0584-8539(95)01421-P.

(71) Chakraborty, M.; Panda, A. K. Spectral Behaviour of Eosin Y in Different Solvents and Aqueous Surfactant Media. Spectrochimica Acta Part A: Molecular and Biomolecular Spectroscopy 2011, 81 (1), 458-465. https://doi.org/10.1016/j.saa.2011.06.038. 
(72) Kasche, V.; Lindqvist, L. Transient Species in the Photochemistry of Eosin*.

Photochemistry and Photobiology 1965, 4 (5), 923-933. https://doi.org/10.1111/j.17511097.1965.tb07941.x.

(73) Acharya, S.; Rebery, B. Fluorescence Spectrometric Study of Eosin Yellow DyeSurfactant Interactions. Arabian Journal of Chemistry 2009, 2 (1), 7-12. https://doi.org/10.1016/j.arabjc.2009.07.010.

(74) Bowers, P. G.; Porter, G. Triplet State Quantum Yields for Some Arom Atic Hydrocarbons and Xanthene Dyes in Dilute Solution. Proc. R. Soc. Lond. A 1967, 299 (1458), 348-353. https://doi.org/10.1098/rspa.1967.0141.

(75) Reindl, S.; Penzkofer, A. Triplet Quantum Yield Determination by Picosecond Laser Double-Pulse Fluorescence Excitation. Chemical Physics 1996, 213 (1), 429-438. https://doi.org/10.1016/S0301-0104(96)00289-3.

(76) Berndt, O.; Bandt, F.; Eichwurzel, I.; Stiel, H. Picosecond Transient Absorption of Xanthene Dyes. Acta Physica Polonica A 1999, 95 (2), 207-220. https://doi.org/10.12693/APhysPolA.95.207.

(77) Bernstein, R.; Foote, C. S. Singlet Oxygen Involvement in the Photochemical Reaction of C60 and Amines. Synthesis of an Alkyne-Containing Fullerene. J. Phys. Chem. A 1999, 103 (36), 7244-7247. https://doi.org/10.1021/jp991534t.

(78) Turro, N. J.; Chow, M. F. Mechanism of Thermolysis of Endoperoxides of Aromatic Compounds. Activation Parameters, Magnetic Field, and Magnetic Isotope Effects. $J$. Am. Chem. Soc. 1981, 103 (24), 7218-7224. https://doi.org/10.1021/ja00414a029.

(79) Gollnick, K.; Schenck, G. O. Mechanism and stereoselectivity of photosensitized oxygen transfer reactions. Pure and Applied Chemistry 1964, 9 (4), 507-526. https://doi.org/10.1351/pac196409040507.

(80) Murasecco-Suardi, P.; Gassmann, E.; Braun, A. M.; Oliveros, E. Determination of the Quantum Yield of Intersystem Crossing of Rose Bengal. Helvetica Chimica Acta 1987, 70 (7), 1760-1773. https://doi.org/10.1002/hlca.19870700712.

(81) Usui, Y. Determination of Quantum Yield of Singlet Oxygen Formation by Photosensitization. Chem. Lett. 1973, 2 (7), 743-744. https://doi.org/10.1246/cl.1973.743.

(82) Al-Nu'airat, J.; Z. Dlugogorski, B.; Gao, X.; Zeinali, N.; Skut, J.; R. Westmoreland, P.; Oluwoye, I.; Altarawneh, M. Reaction of Phenol with Singlet Oxygen. Physical Chemistry Chemical Physics 2019, 21 (1), 171-183. https://doi.org/10.1039/C8CP04852E. 